\title{
Short Pulse Laser Production of Diamond Thin Films
}

P.S. Banks, B.C. Stuart, L. Dinh, M.D. Feit, A.M. Rubenchik, W. McLean, M.D. Perry

\section{March 20, 1998}

U.S. Department of Energy

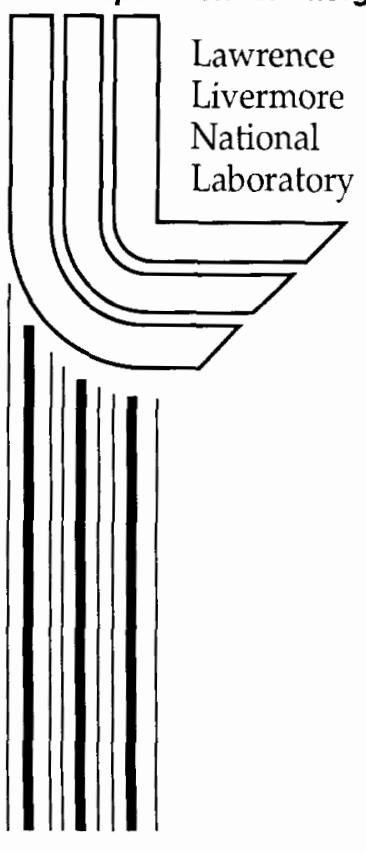




\section{DISCLAIMER}

This document was prepared as an account of work sponsored by an agency of the United States Government. Neither the United States Government nor the University of California nor any of their employees, makes any warranty, express or implied, or assumes any legal liability or responsibility for the accuracy, completeness, or usefulness of any information, apparatus, product, or process disclosed, or represents that its use would not infringe privately owned rights. Reference herein to any specific commercial product, process, or service by trade name, trademark, manufacturer, or otherwise, does not necessarily constitute or imply its endorsement, recommendation, or favoring by the United States Government or the University of California. The views and opinions of authors expressed herein do not necessarily state or reflect those of the United States Government or the University of California, and shall not be used for advertising or product endorsement purposes.

This work was performed under the auspices of the U. S. Department of Energy by the University of California, Lawrence Livermore National Laboratory under Contract No. W-7405-Eng-48.

This report has been reproduced directly from the best available copy.

Available electronically at http://www.doe.gov/bridge

Available for a processing fee to U.S. Department of Energy

and its contractors in paper from

U.S. Department of Energy

Office of Scientific and Technical Information

$$
\text { P.O. Box } 62
$$

Oak Ridge, TN 37831-0062

Telephone: (865) 576-8401

Facsimile: (865) 576-5728

E-mail: reports@adonis.osti.gov

Available for the sale to the public from

U.S. Department of Commerce

National Technical Information Service

5285 Port Royal Road

Springfield, VA 22161

Telephone: (800) 553-6847

Facsimile: (703) 605-6900

E-mail: orders@ntis.fedworld.gov

Online ordering: http://www.ntis.gov/ordering.htm

OR

Lawrence Livermore National Laboratory

Technical Information Department's Digital Library

http://www.llnl,gov/tid/Library.html 


\title{
Short Pulse Laser Production of Diamond Thin Films
}

\author{
P. S. Banks, B. C. Stuart, L. Dinh, M. D. Feit, A. M. Rubenchik, W. McLean, M. D. Perry
}

The use of diamond thin films has the potential for major impact in many industrial and scientific applications. These include heat sinks for electronics, broadband optical sensors, windows, cutting tools, optical coatings, laser diodes, cold cathodes, and field emission displays. Attractive properties of natural diamond consist of physical hardness, high tensile yield strength, chemical inertness, low coefficient of friction, high thermal conductivity, and low electrical conductivity. Unfortunately, these properties are not completely realized in currently produced diamond thin films.

Chemical vapor deposition, in its many forms, has been the most successful to this point in producing crystalline diamond films microns to millimeters in thickness which are made up of closely packed diamond crystals microns in physical dimension. However, high purity films are difficult to realize due to the use of hydrogen in the growth process which becomes included in the film matrix. These impurities are manifest in film physical properties which are inferior to those of pure crystalline diamond. In addition, the large density of grain boundaries due to the polycrystalline nature of the films reduce the films' diamond-like character. Finally, substrates must be heated to several hundred degrees Celsius which is not suitable for many materials.

Pulsed laser deposition is attractive due to its ability to produce high purity films-limited only by the purity of the target. For diamond film production, high purity carbon can be ablated directly by lasers and deposited as thin films at ambient temperatures. However, lasers currently in use generally deliver long ( $>10 \mathrm{~ns}$ ) pulses, and the generally explosive nature of laser ablation, in addition to the desired single-atom or single-ion carbon, liberates significant amounts of carbon 
clusters $\left(C_{n}\right.$ where $\left.n=2-30\right)$ and macroscopic particles $(>1-10 \mu \mathrm{m})$ of carbon. These carbon particles interrupt the ordered deposition of crystalline diamond, forming undesirable grain boundaries and rough surfaces that are difficult to polish. In addition, PLD generated films tend to be "amorphous" or nanocrystalline with no observable long-range order, but still possessing physical properties which are diamond-like in some approximation. This has given rise to the term "diamond-like carbon" when referring to these PLD-produced, amorphous carbon films. Growth rates for PLD have been prohibitively slow until recently with the advent of high average power, high rep-rate lasers. ${ }^{1}$

There has been evidence that increasing laser intensity, and thus particle kinetics, leads to DLC film which are increasingly more diamond-like in character. ${ }^{2,3}$ Given that short pulse (subpicosecond) lasers can reach intensities much higher than those achievable with conventional lasers, combined with the fact that that laser ablation using short pulses is relatively gentle, ${ }^{4}$ short pulse PLD holds promise as a technique of producing high quality films with properties very close to that of crystalline diamond. Some work has already shown that the plasma generated using femtosecond lasers is composed of single atom ions with no clusters ${ }^{5}$ producing films with high $s p^{3} / s p^{2}$ ratios. ${ }^{6}$ Using a high average power femtosecond laser system at LLNL, we were able to dramatically increase deposition rates to up to $25 \mu \mathrm{m} / \mathrm{hr}$ (which exceeds many CVD processes) while growing particulate-free films. We also determined deposition rates as a function of laser wavelength, laser fluence, laser spot size, and target/substrate separation, determined the relevant laser parameters to ensure particulate-free growth, and characterized the films grown using several diagnostic techniques including electron energy loss spectroscopy (EELS) and Raman spectroscopy. Finally, the nonthermal processes involved in femtosecond laser ablation prove ideal for laser machining of high explosives, and some pellets of explosive materials were cut.

\section{Experiment}




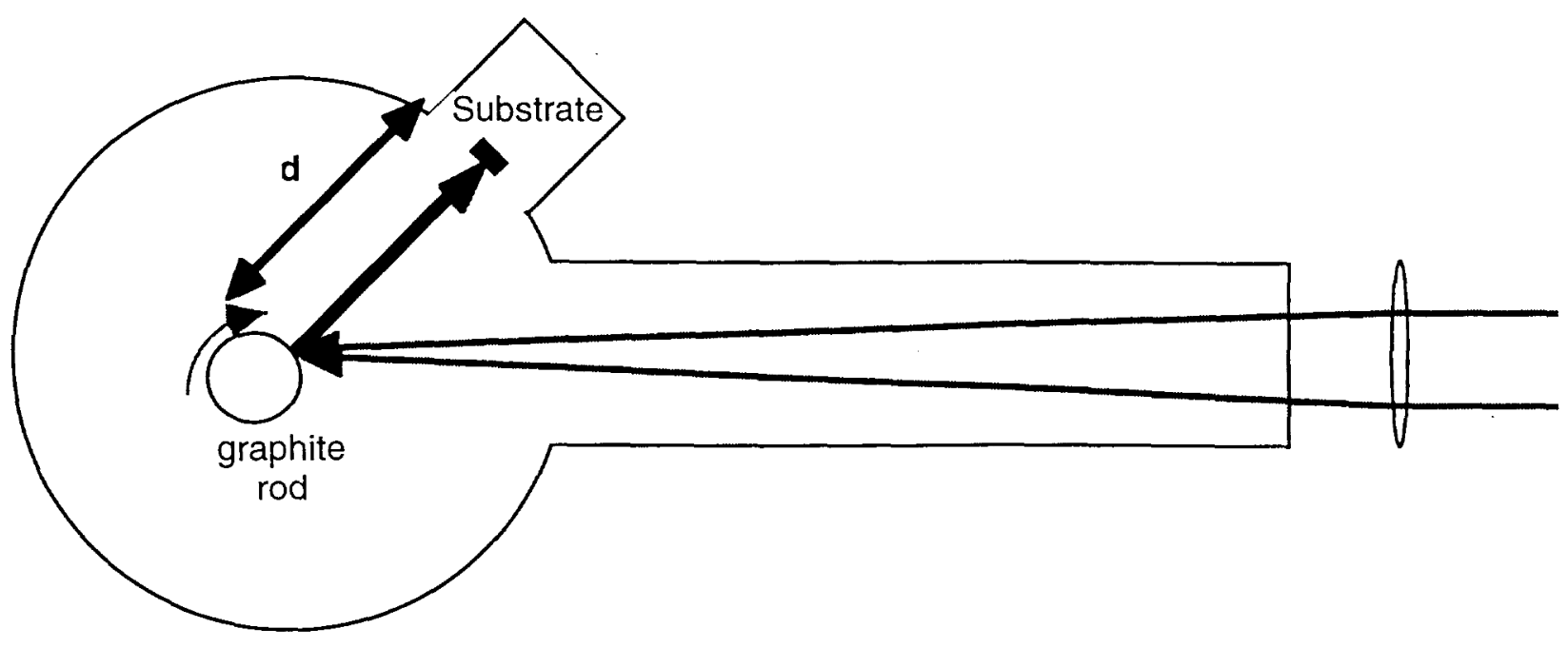

Fig. 1. Cross section of deposition chamber

The laser system used for ablating the graphite target used for the experiments is a 3-4 W average power, $120 \mathrm{fs}$ laser system. It is a chirped-pulse-amplification system that uses a Ti:sapphire regenerative amplifier operating at $1 \mathrm{kHz}$ repetition rate, thus providing a millijoulelevel pulse every millisecond. The experiments were conducted in a vacuum chamber (a 6" diameter sphere) at a base pressure of .5-5 $\mu$ torr, the cross-section of which is shown in Fig. 1. A 1" diameter graphite rod was rotated about it's longitudinal axis (perpendicular to the laser beam) while the beam impinged on the rod at a $45^{\circ}$ angle of incidence. The resulting plasma plume was directed as well as possible toward the substrate which was held in place by an aluminum annulus with a $12 \mathrm{~mm}$ inside diameter and a $25 \mathrm{~mm}$ outside diameter. The rod could also be translated along it's long axis at $400 \mu \mathrm{m} / \mathrm{s}$ so that the laser pulse was incident on a nominally flat surface. The distance from the graphite surface to the substrate surface (denoted by $d$ in Fig. 1) was varied from $31 \mathrm{~mm}$ to $85 \mathrm{~mm}$ by moving the substrate assembly in or out. A $45 \mathrm{~cm}$ focal length, planoconvex lens was used to control the spot size on the target surface with the beam waist located behind the ablation surface.

The laser beam is nearly diffraction-limited, and the spot size on the graphite surface was determined by calculating the ideal gaussian spot size at a distance $x$ from the waist position. The 
waist position was determined by reducing the fluence incident on the target and moving the lens to maximize the brightness of the plasma observed.

The spot size on the target was then adjusted by moving the lens closer to the target by the
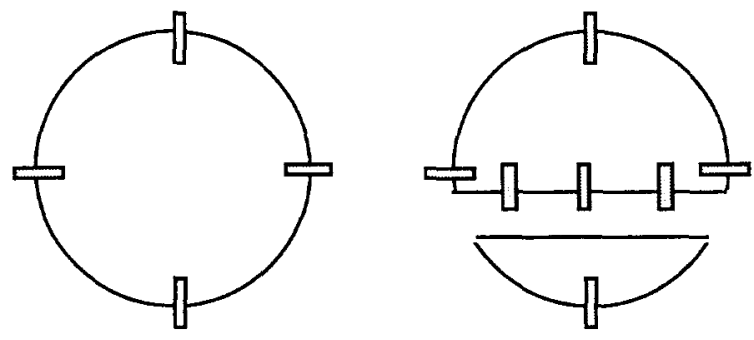
appropriate amount. The energy incident on the target was also varied, as was the incident Fig. 2. Thickness measurement positions. Shaded rectangles indicate edge positions where film thickness was measured. polarization (s and p linear polarizations as well as circularly polarized).

The films were grown on single crystal silicon wafers which had been cleaved into $15 \mathrm{~mm}$ squares as well as on polished fused quartz substrates. Substrate preparation usually consisted of cleaning with methanol or acetone although the effect of etching with $\mathrm{HF}$ acid was investigated. It was also possible to electrically bias the substrate assembly and, using a current probe, measure the current due to the plasma striking the substrate. After growth, the film thicknesses were measured, deposition rates determined, and EELS, Raman spectroscopy, optical transmission, spectral ellipsometry, UV photoelectron spectroscopy, and Auger spectroscopy were used to determine how "diamond-like" the films were. Scanning electron microscopy and atomic force microscopy were also used to examine the surface morphology.

\section{Results}

Rate. Films of thickness ranging from $20 \mathrm{~nm}$ to $18 \mu \mathrm{m}$ were grown in this fashion for incident fluences varying from $.1 \mathrm{~J} / \mathrm{cm}^{2}$ to $30 \mathrm{~J} / \mathrm{cm}^{2}$ and spot sizes from $50 \mu \mathrm{m}$ to $600 \mu \mathrm{m}$. The film thickness was measured using a Tencor P-10 surface profiler along the outside circumference of the films. Many of the films were also grown with a mask (a $3 \mathrm{~mm}$ wide strip of stainless steel) positioned $3 \mathrm{~mm}$ above the substrate surface, allowing the step height to be measured along the resulting edge and determination of any thickness variation across the film (see Fig. 2). It was found that the substrate diameter was too small for there to be any pronounced variation in film 
thickness across the sample. The only instances where thickness variations were observed were where the center of the plasma plume was not directed at the center of the substrate. This resulted in a monotonically increasing thickness across the sample in some direction. This also indicates that the plume and resulting film are quite sharply peaked.

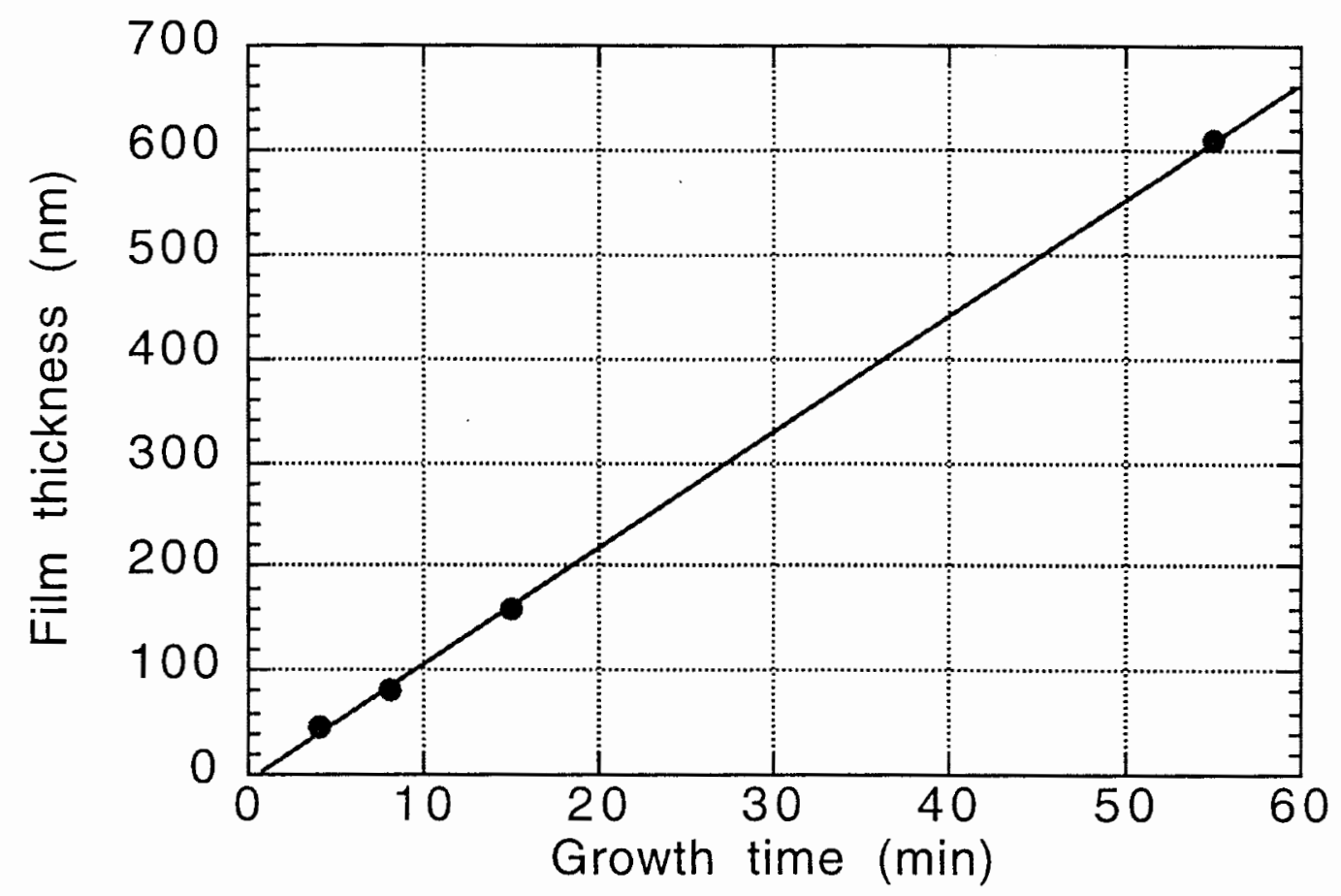

Fig. 3. Growth rate as a function of time. The conditions were $250 \mathrm{~mm}$ spot at $1.4 \mathrm{~J} / \mathrm{cm}^{2}$ and a $75 \mathrm{~mm}$ target/substrate separation. The line is a linear fit to the data.

By growing films under several different conditions and measuring the resultant film thickness, it was possible to establish the effect of these parameters. The rate was determined by dividing the maximum thickness measured by the elapsed time for the growth process. To verify that the growth rate did not change with thickness, several films were grown under the same conditions for several different times as shown in Fig. 3. Thus, the rates obtained should be valid, independent of film thickness or growth time. 


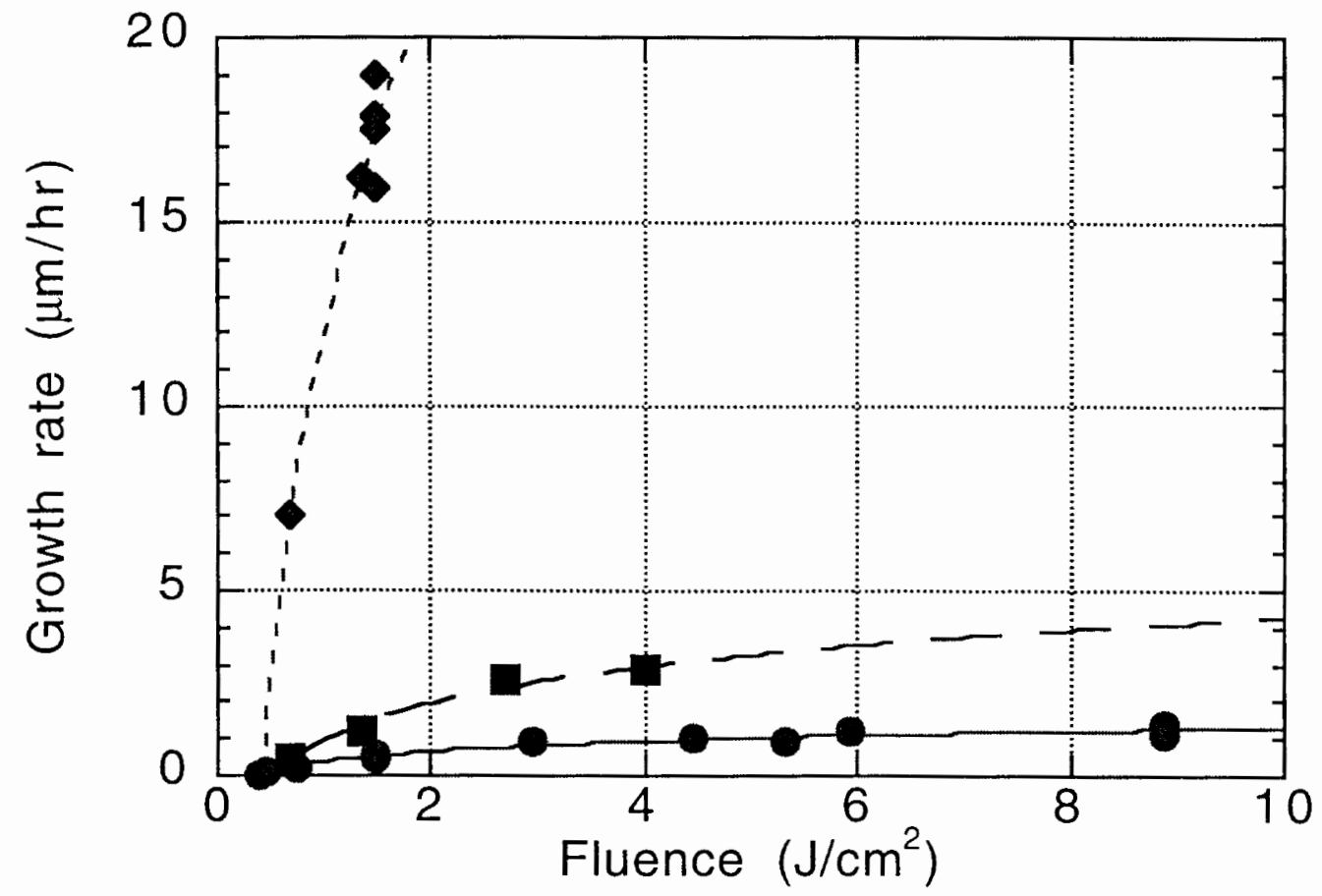

Fig. 4. Growth rate as a function of incident laser fluence. The dots are for a $250 \mu \mathrm{m}$ spot with a $75 \mathrm{~mm}$ target/substrate separation, the squares are for a $370 \mu \mathrm{m}$ spot and $75 \mathrm{~mm}$ separation, and the diamonds are for a $630 \mu \mathrm{m}$ spot and a $31 \mathrm{~mm}$ separation. The line is a logarithmic fit to the data.

Rates were measured as a function of laser fluence on the graphite target, laser spot size on the target surface, and the distance between the target and substrate surfaces, and the results are shown in Figs. 4-6. As seen in Fig. 4, the growth rate saturates quickly at laser fluences above a few $\mathrm{J} / \mathrm{cm}^{2}$. There is, however, an indication of how significant the target/substrate separation and spot size is to increasing growth rates. Higher fluences for the larger spot sizes were not possible due to laser power limitations. Fig. 5 shows a linear relationship between growth rate and the area of the material removal region (as determined by the laser spot size) for a given fluence $\left(1.4 \mathrm{~J} / \mathrm{cm}^{2}\right)$. As discussed previously, this is because the larger transverse dimensions of the initial plasma results in slower transverse expansion and a higher flux incident on the substrate. This increase in flux is also the reason that reducing the distance between the target and substrate results in dramatically larger growth rates. This is where sub-picosecond lasers have a large advantage over conventional 
PLD. Since the initial plasma is ideally composed of single atom ions, there are no macroparticulates present which will contaminate the film as it grows. It is no longer necessary to maintain large separations nor use buffer gases to reduce the impact of these macroparticles.

In addition to these experimental conditions, the substrate material had a significant effect on the growth rate of the films. Both crystalline silicon and fused quartz substrates were used, and the

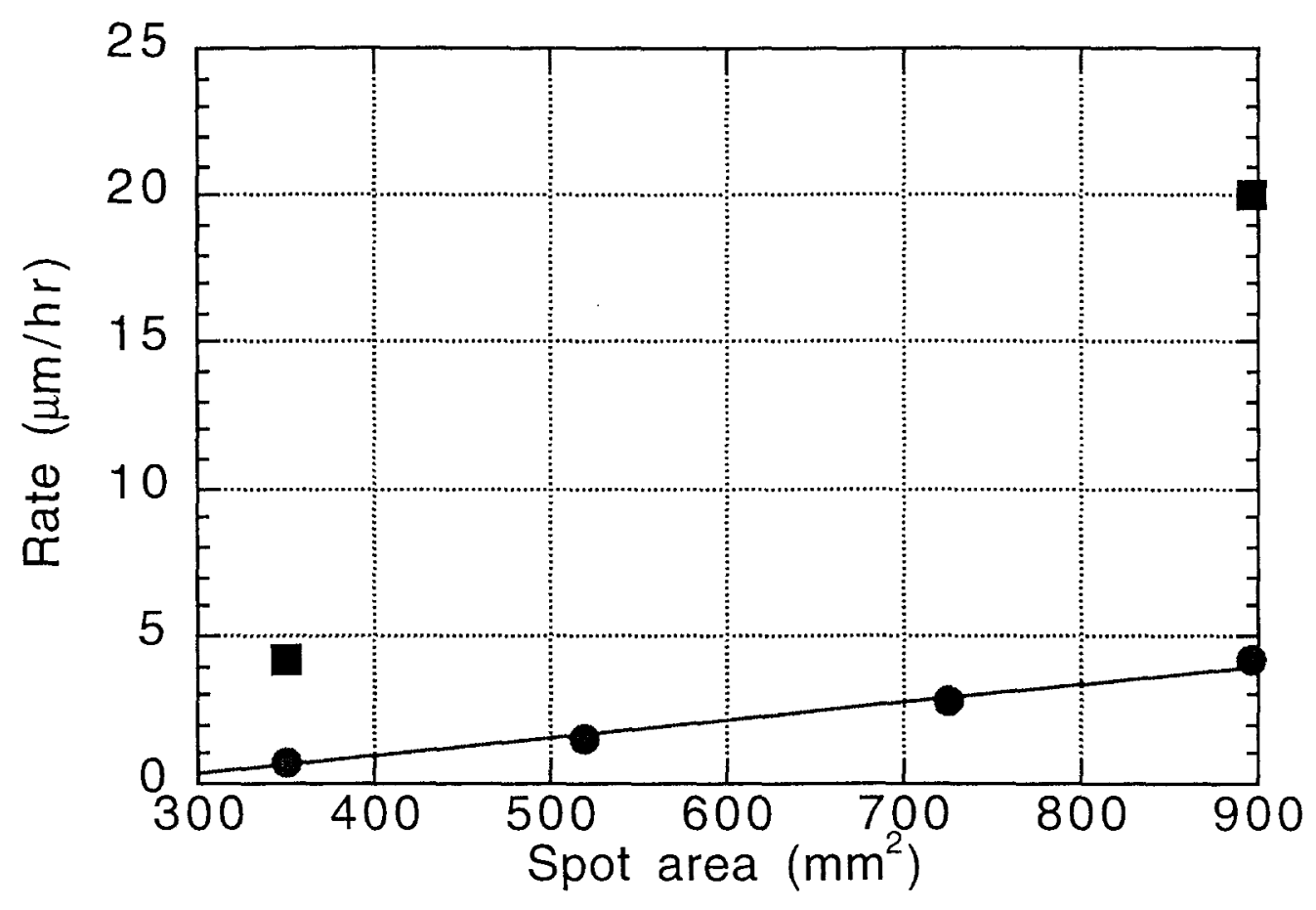

Fig. 5. Growth rate as a function of area of laser spot size (defined at $1 / \mathrm{e}^{2}$ point) at 1.4 $\mathrm{J} / \mathrm{cm}^{2}$. The dots are for $75 \mathrm{~mm}$ target/substrate separation and the squares are for $31 \mathrm{~mm}$ separation. The line is a linear fit of the data.

rates for films grown on the quartz substrates were approximately $20-30 \%$ higher than those grown on the silicon. This held true for films from $50 \mathrm{~nm}$ thick to films over a micron thick. Perhaps the amorphous structure of the quartz is more closely matched to that of the DLC films than the silicon, although there were no observable differences in the film properties. We also investigated the effects of surface preparation on the growth of DLC films. We etched the surface of the silicon with $1 \%-10 \% \mathrm{HF}$ acid for 1 to 60 minutes, and then stored the substrates in a nitrogen atmosphere until use. No change in growth rates nor film morphology was observed 
when compared with those of films grown on silicon that had only been cleaned with acetone or methanol.

Finally, we also observed a small dependence of deposition rate on the polarization of the incident laser light. The use of S-polarized light resulted in a growth rate approximately $20 \%$ lower than that achieved when using P-polarized or circularly polarized light. This is likely due to less of the laser energy being absorbed by the graphite because of a higher fresnel reflectivity for Spolarization. Macroparticulates, apparently from the target, were also seen when using S-polarized

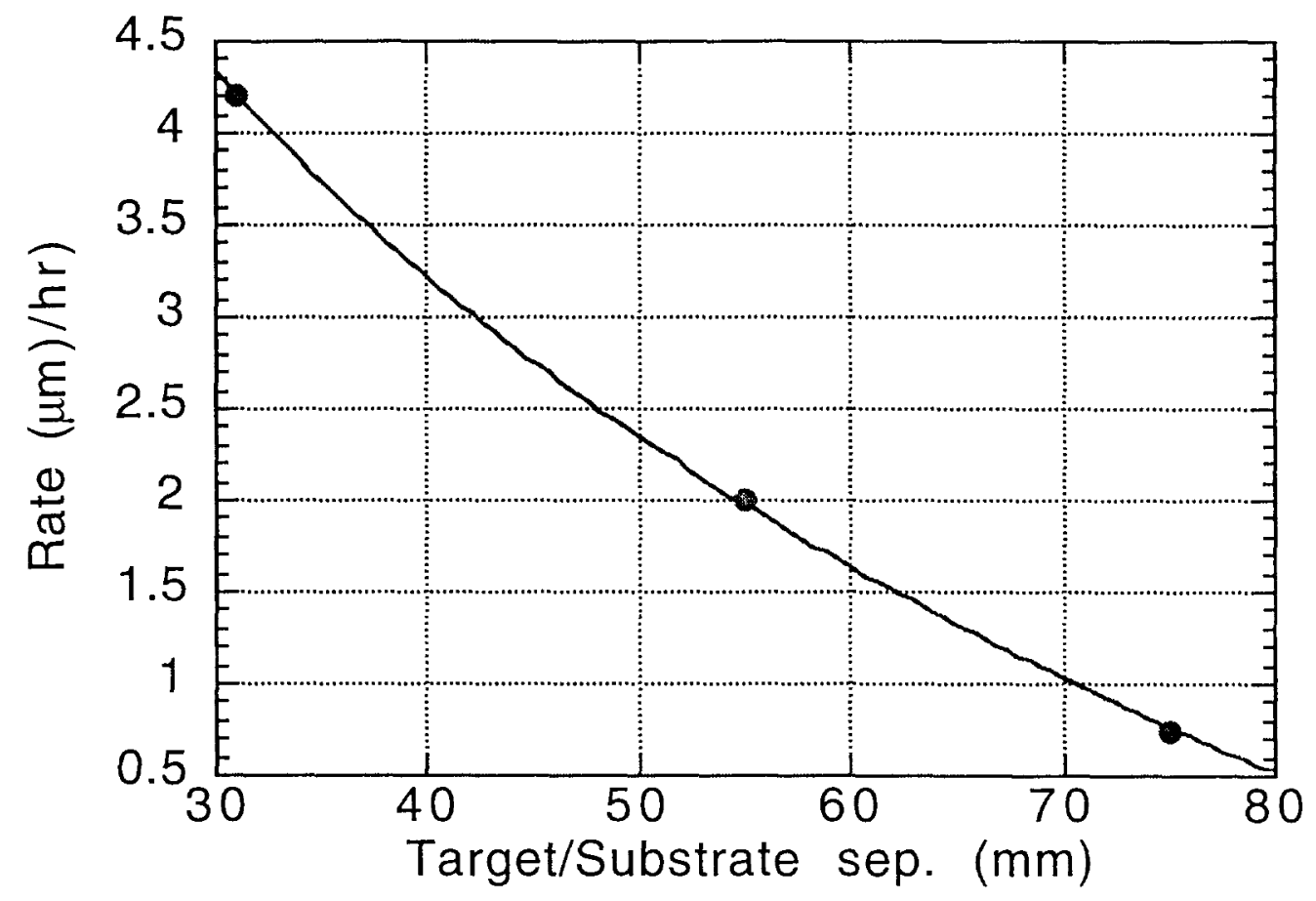

Fig. 6. Film growth rate as a function of separation distance between target and substrate for $1.4 \mathrm{~J} / \mathrm{cm}^{2}$ and $250 \mu \mathrm{m}$ spot. The line is a logarithmic fit to the data.

light. Also, the rate achieved using the second harmonic $(413 \mathrm{~nm})$ was only one fifth that realized using the fundamental. 


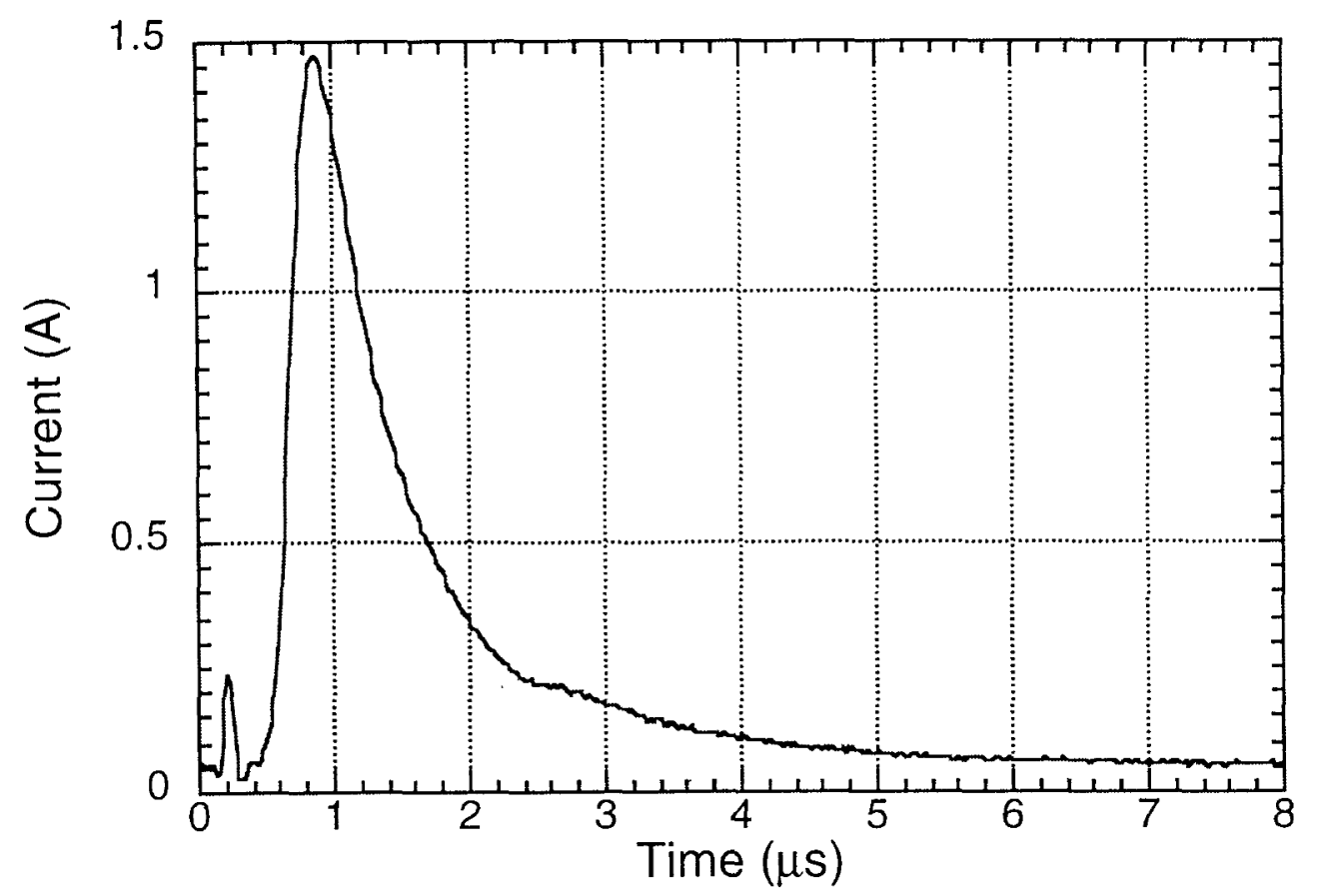

Fig. 7. Current measured for $25 \mathrm{~J} / \mathrm{cm}^{2}, 150 \mu \mathrm{m}$ spot at $75 \mathrm{~mm}$ separation. The laser pulse was incident on target at $\mathrm{t}=0.0 \mu \mathrm{s}$.

Plasma diagnostics. The substrate was biased to $-300 \mathrm{~V}$, and a current probe was used to measure the current due to the plasma reaching the substrate. This measurement allows an estimate of the percentage of the plasma which is charged as well as the determination of the velocity distribution. Fig. 7 shows the current pulse measured for $25 \mathrm{~J} / \mathrm{cm}^{2}, 150 \mu \mathrm{m}$ spot and $75 \mathrm{~mm}$ target/substrate separation. The small peak at $200 \mathrm{~ns}$ is electrical noise from the firing of the pulsed bias supply. Integrating to find the area under the curve gives $1.5 \mu \mathrm{C}$ of charge delivered to the substrate during the pulse. The film grown under these conditions is $44 \mathrm{~nm}$ thick (uniformly) after 6:00 minutes. The substrate and holder have an area of $8 \mathrm{~cm}^{2}$ so if a uniform thickness is assumed across this region, the volume of material delivered in this time is $3.5 \times 10^{-5} \mathrm{~cm}^{3}$ (assuming $100 \%$ of material sticks and is incorporated in the film). The typical density of graphite or diamond is 2-3 $\mathrm{g} / \mathrm{cm}^{3}$ so $3 \mathrm{~g} / \mathrm{cm}^{3}$ will give an overestimate. Using this latter value gives $.106 \mathrm{mg}$ and therefore 5.3 $\times 10^{18} \mathrm{C}$ atoms delivered to the substrate and holder in 6:00 minutes. The total charge would be 
$1.5 \mu \mathrm{C}$ times 360,000 pulses or $.54 \mathrm{C}$ which corresponds to $3.38 \times 10^{18}$ charge quanta. If we assume that each ion is singly ionized, this estimate indicates that ions make up approximately $65 \%$ of the plasma when it reaches the substrate $75 \mathrm{~mm}$ from the target surface.

This is much higher than anything reported for the use of long pulse PLD where a few percent is good. However, there are many unknowns in this calculation, most importantly the fraction of particles in the plasma which stick to the substrate at first impact and are not reflected elsewhere in the chamber. It is possible that the majority of particles delivered are not captured, particularly with the high kinetic energies that these particles have (as will be described next). It should also be noted that at lower laser fluences (e.g. $2 \mathrm{~J} / \mathrm{cm}^{2}$ ), the ion fraction becomes a fraction of a percent. It does not, however, vary significantly between $38 \mathrm{~mm}$ and $75 \mathrm{~mm}$ from the target. This would indicate that there is not much recombination occurring after that point.

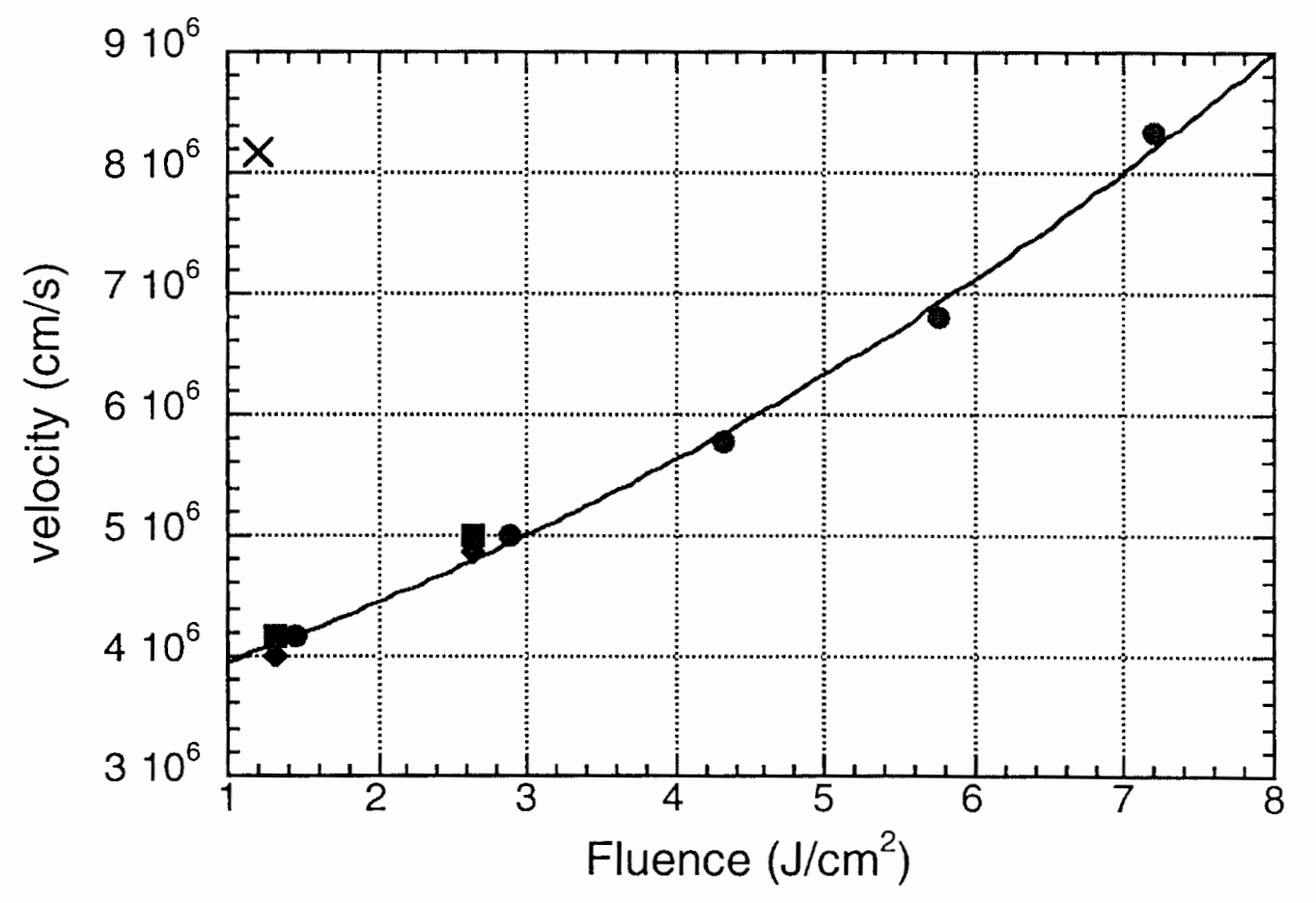

Fig. 8. Velocity of peak of current pulse as a function of laser fluence. The dots are for a $250 \mu \mathrm{m}$ spot at $75 \mathrm{~mm}$ separation, the squares are for a $370 \mu \mathrm{m}$ spot at $75 \mathrm{~mm}$ separation, the diamonds are for a $370 \mu \mathrm{m}$ spot at $38 \mathrm{~mm}$ separation, and the $\times$ is for a $250 \mu \mathrm{m}$ spot at $31 \mathrm{~mm}$ separation with $413 \mathrm{~nm}$ light. The line is an exponential fit to the data. 
Fig. 7 also gives the velocity distribution for the plasma incident on the substrate. Assuming that the velocity of the plasma expansion quickly approaches an asymptotic value within a few hundred microns, the target/substrate separation divided by the time delay from laser pulse to current signal will give the velocity at which the particles are traveling. The value of the velocity of the peak of the distribution is plotted as a function of laser fluence in Fig. 8. It is apparent that the most probable velocity is independent of spot size or separation so that the particles have reached their asymptotic velocity well before $38 \mathrm{~mm}$. Carbon ions traveling at speeds of 40 to $80 \mathrm{~km} / \mathrm{s}$ correspond to kinetic energies of 100 to $400 \mathrm{eV}$.

It is also apparent that using $413 \mathrm{~nm}$ light rather than $825 \mathrm{~nm}$ light more than doubles the velocity. The only possible explanations thus far are first, the skin depth for $2 \omega$ light is smaller resulting in a smaller ablation depth although the exact relationship between skin depth and ablation depth is unknown and second, the graphite target has higher absorption at $2 \omega$. Let the refractive index $n_{0}$ be defined as $n_{0}=n+k$, and for graphite (ordinary polarized light), $n=3.1$ for $825 \mathrm{~nm}$ and 2.6 for $413 \mathrm{~nm}$ and $k=1.9$ for $825 \mathrm{~nm}$ light and 1.3 for $413 \mathrm{~nm} .^{7}$ The skin depth is defined by $\delta=n \lambda(2 \pi k)$ and is $200 \mathrm{~nm}$ for $825 \mathrm{~nm}$ light and $130 \mathrm{~nm}$ for $413 \mathrm{~nm}$ light. The fact that the deposition rate at $413 \mathrm{~nm}$ is much lower may also indicate that the ablation depth at this wavelength is significantly smaller than at $825 \mathrm{~nm}$.

The complex reflection coefficients for a conducting medium are

$$
\begin{aligned}
& r_{s}=\frac{\cos \theta_{1}-(n+k) \cos \theta_{2}}{\cos \theta_{1}+(n+k) \cos \theta_{2}} \text { and } \\
& r_{p}=\frac{(n+k) \cos \theta_{1}-\cos \theta_{2}}{(n+k) \cos \theta_{1}+\cos \theta_{2}} \\
& \text { where } \cos \theta_{2}=\sqrt{1-\frac{\sin ^{2} \theta_{1}}{(n+k)^{2}}}
\end{aligned}
$$


and $\theta_{1}$ is the angle of incidence $\left(45^{\circ}\right.$ in this case). For $825 \mathrm{~nm}$ light, $\left|\mathrm{r}_{\mathrm{p}}\right|^{2}=.27$ and $\left|\mathbf{r}_{\mathrm{s}}\right|^{2}=.52$ while for $413 \mathrm{~nm}$ light, $\left|\mathrm{r}_{\mathrm{p}}\right|^{2}=.17$ and $\left|\mathrm{r}_{\mathrm{s}}\right|^{2}=.42$. This makes the absorptance $\left(1-|\mathrm{r}|^{2}\right)$ for graphite at 413 $\mathrm{nm}$ approximately $15-20 \%$ larger than for $825 \mathrm{~nm}$.

Morphology. The physical morphology of each film was also examined using both optical and electron microscopy and atomic force microscopy (AFM). The chemical composition of the films were examined using electron energy loss spectroscopy (EELS), Raman spectroscopy, optical transmission measurements, ellipsometry, Auger spectroscopy, and UV photoelectron spectroscopy (UPS). Particularly with the chemical analysis, a comparison was made with the properties expected for crystalline diamond, graphite, or the typical amorphous carbon films made using CVD and PLD.

Using femtosecond pulses, we were able to produce films which are free of graphite particulates which have characterized PLD growth of DLC films. Fig. 9 is an optical photomicrograph of a $250 \mathrm{~nm}$ thick DLC film which has almost no visible graphite particulates. There is also no observable structure on the surface or when cross sectioned. Fig. 10 shows two views of the cross section of a film. Of particular interest is the large particle in Fig. 10(a) which must have been a small piece of dirt present on the substrate before coating. The film appears to be uniform around the particle, even on the side walls.

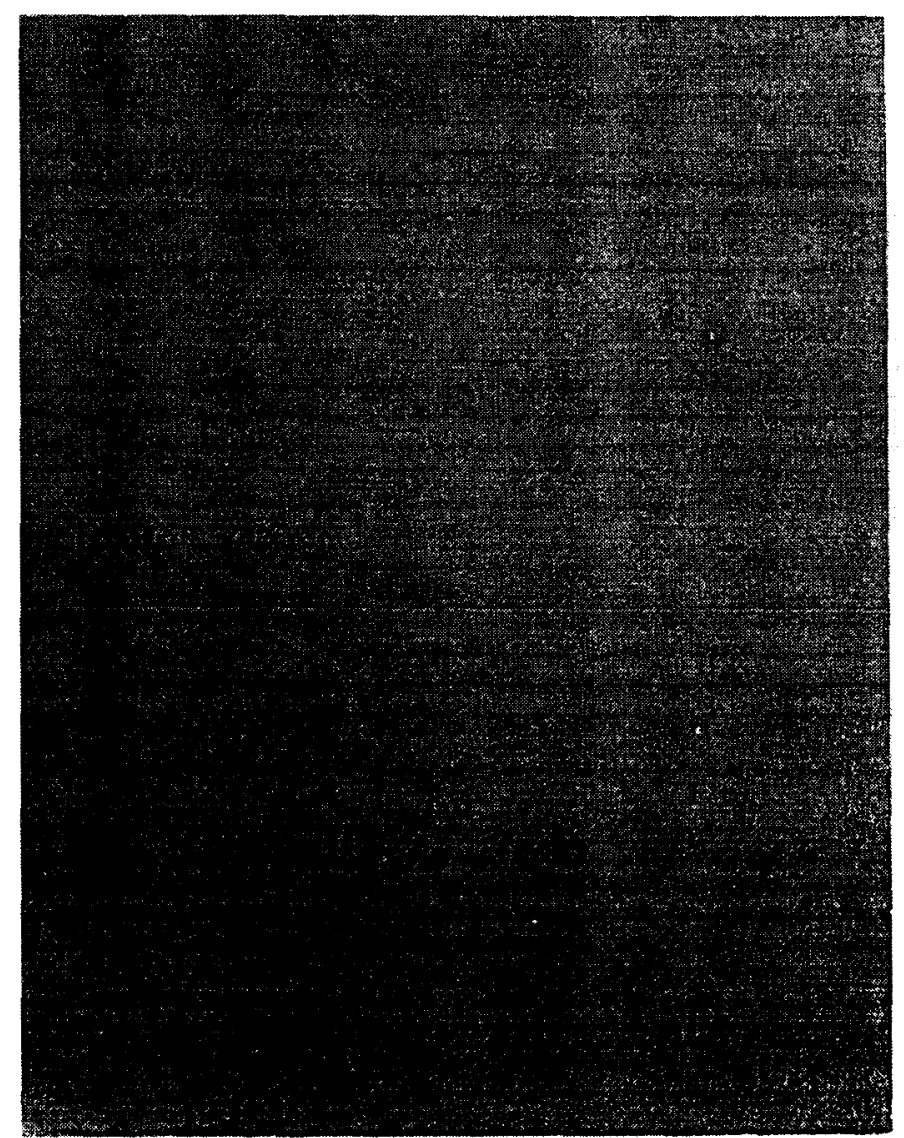

Fig. 9. Optical photomicrograph of DLC film. The image is $220 \mu \mathrm{m}$ by $280 \mu \mathrm{m}$ (400X). 

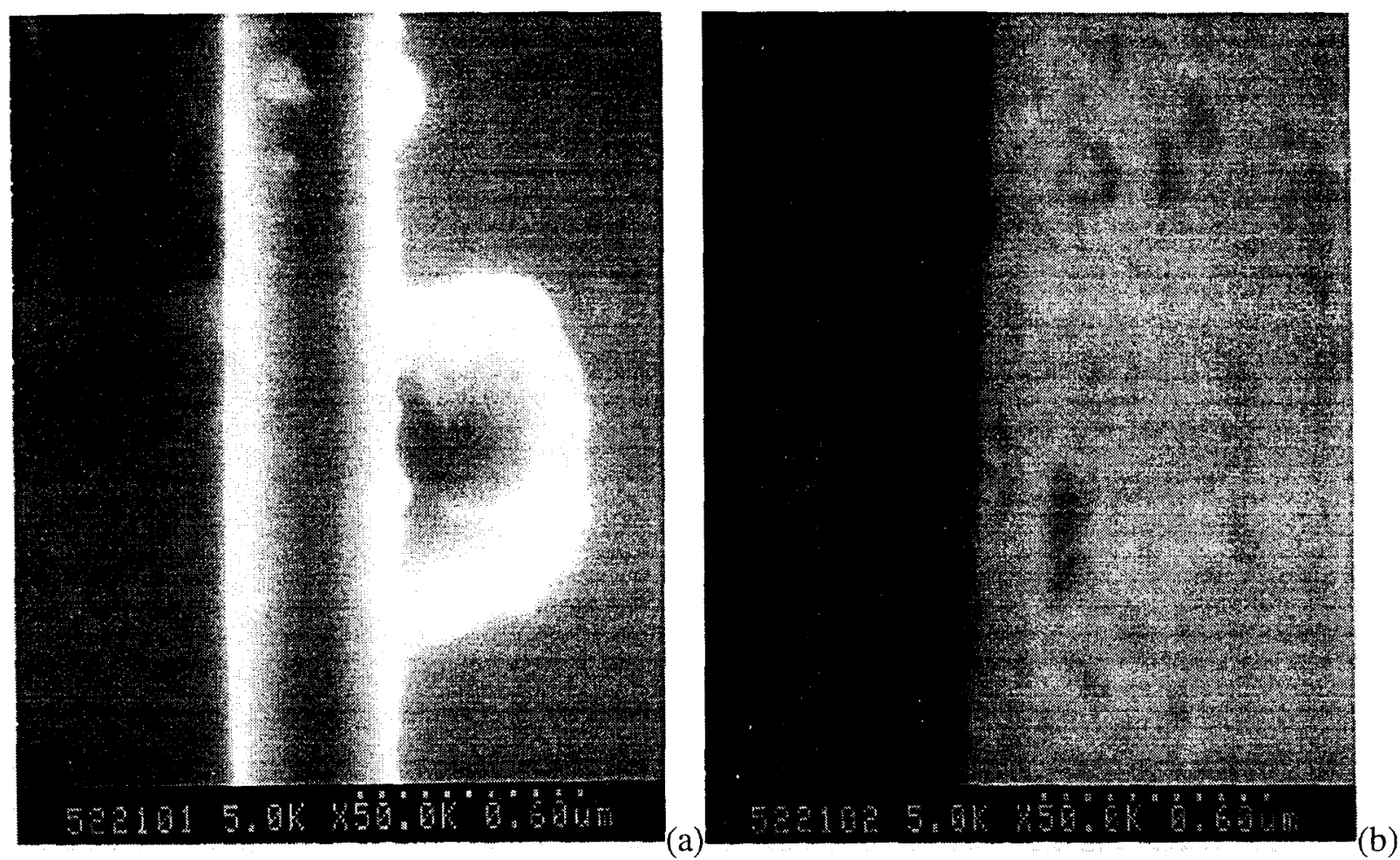

Fig. 10. Electron photomicrographs of cross section of DLC film.

As mentioned before, the use of P-polarized or circularly polarized light is useful for the prevention of the presence of particulates in the films.

However, as the films grows thicker (>500 nm), a cauliflower-like surface texture begins to form which becomes more pronounced as the film grows. This can be seen in Fig. 11 which is the edge of a film which is $20 \mu \mathrm{m}$ thick. Films thicker than $3-5 \mu \mathrm{m}$ showed a tendency to lift-off the substrate with quartz being more susceptible to this. There was also a tendency for the films to crack and shatter due to internal stresses. This is typical of PLD-produced films, but occurs at much smaller thicknesses (less than $1 \mu \mathrm{m}$ ) for long-pulse PLD. As shown in Fig. 11, intact films up to $20 \mu \mathrm{m}$ were grown (although there was some cracking and lift-off in certain regions), and free standing films which had lifted off were produced with areas of $10-20 \mathrm{~mm}^{2}$ and larger.

Atomic force microscopy was used to measure the surface roughness of three films: 


\begin{tabular}{cccc} 
Film & Thickness $(\mathrm{nm})$ & Growth rate $(\mu \mathrm{m} / \mathrm{hr})$ & RMS roughness $(\mathrm{nm})$ \\
\hline 1 & 20 & .35 & .5 \\
2 & 30 & .55 & 1 \\
3 & 210 & 1.2 & 1.5
\end{tabular}

Fig. 12 shows the results of this type of scan where the edge of the film is shown with the uncoated Si surface on the right. It is apparent that the presence of small bumps in the deposited film is due to the presence of contaminants on the original silicon surface (which had been masked). The density and size and approximately the same for the film surface and for the silicon surface. Similar measurements done using the profilometer showed that the RMS surface roughness of a film was typically on the order of $1 \%$ of the film thickness. As discussed earlier, the ease with which the films conform to the surface would indicate that to first order, they would be as smooth as the substrate surface they are grown on. The development of the surface texture is most likely due to the growth in the size of the nanocrystals and a high defect concentration.

In order to determine the chemical structure of the films produced, EELS and Raman spectroscopy are two popular techniques to determine the amount of diamond-like $s p^{3}$ bonds present in the film. EELS looks at the inelastic scattering of high energy electrons by plasmons with the



Fig. 11. Electron photomicrograph of $18 \mu \mathrm{m}$ thick DLC film. The cauliflower-like surface texture is typical of thicker films. 


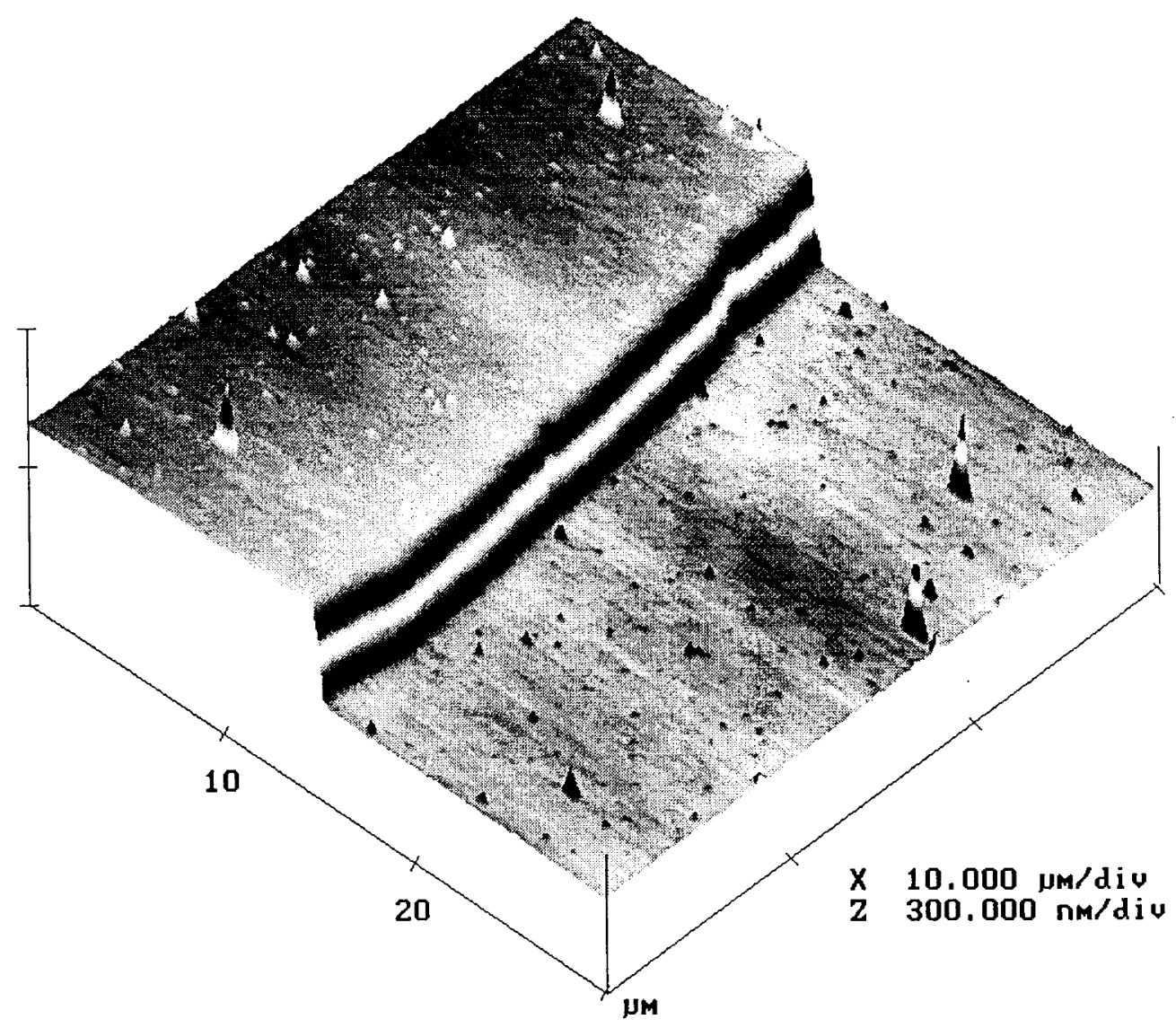

Fig. 12. AFM scan of edge of $200 \mathrm{~nm}$ thick DLC film. The area to the right is the surface of the silicon substrate.

shift in energy being indicative of the type of bond present. Fig. 13 shows some characteristic

EELS signatures of crystalline diamond, graphite, and amorphous carbon (both diamond-like and graphitic) films. The $s p^{2}$ bond of graphite shows up as a peak at about $5 \mathrm{eV}$ as seen in the lower two curves. Fallon and Brown, for CVD produced films, have correlated the amount that the large peak is shifted to the fraction of the material which is $s p^{3}$ bonded. ${ }^{8}$

EELS measurements of femtosecond PLD-produced films show no graphitic content (see Fig. 14) with plasmon shifts of $21 \mathrm{eV}$ to $26 \mathrm{eV}$.

\begin{tabular}{cccccc} 
Film & $\begin{array}{c}\text { Plasmon } \\
\text { shift }(\mathrm{eV})\end{array}$ & $\begin{array}{c}\text { Fluence } \\
\left(\mathrm{J} / \mathrm{cm}^{2}\right)\end{array}$ & $\begin{array}{c}\text { Film thickness } \\
(\mathrm{nm})\end{array}$ & polarization & rate $(\mu \mathrm{m} / \mathrm{hr})$ \\
\hline 1 & 26 & .4 & 420 & $\mathrm{~s}$ & .21 \\
2 & 23 & 12 & 710 & $\mathrm{~s}$ & 1.4
\end{tabular}




$\begin{array}{cccccc}3 & 22 & 12 & 570 & \mathrm{~s} & 1.2 \\ 4 & 25 & 4 & 470 & \mathrm{~s} & .9 \\ 5 & 20 & 8 & 200 & \mathrm{c} & 1.2 \\ 6 & 21 & 2 & 18000 & \mathrm{c} & 9 \\ 7 & 21 & 1.7 & 330 & \mathrm{p} & .6\end{array}$

The last line is for $413 \mathrm{~nm}$ light. It would appear that s-polarization or lower fluences produce films with a larger plasmon shift, indicating a higher $s p^{3}$ content. This trend is contradicted, as will be discussed later, by the films produced at higher fluences becoming more optically transparent.

Raman spectroscopy is another common tool because the Raman signal from crystalline diamond and graphite are very distinct. Diamond has a very narrow, sharp peak near $1330 \mathrm{~cm}^{-1}$ while graphite is characterized by two broad peaks centered near $1400 \mathrm{~cm}^{-1}$ and $1600 \mathrm{~cm}^{-1}$ (see Fig. 15). Amorphous carbon films, regardless of how they are produced, tend to have a structure

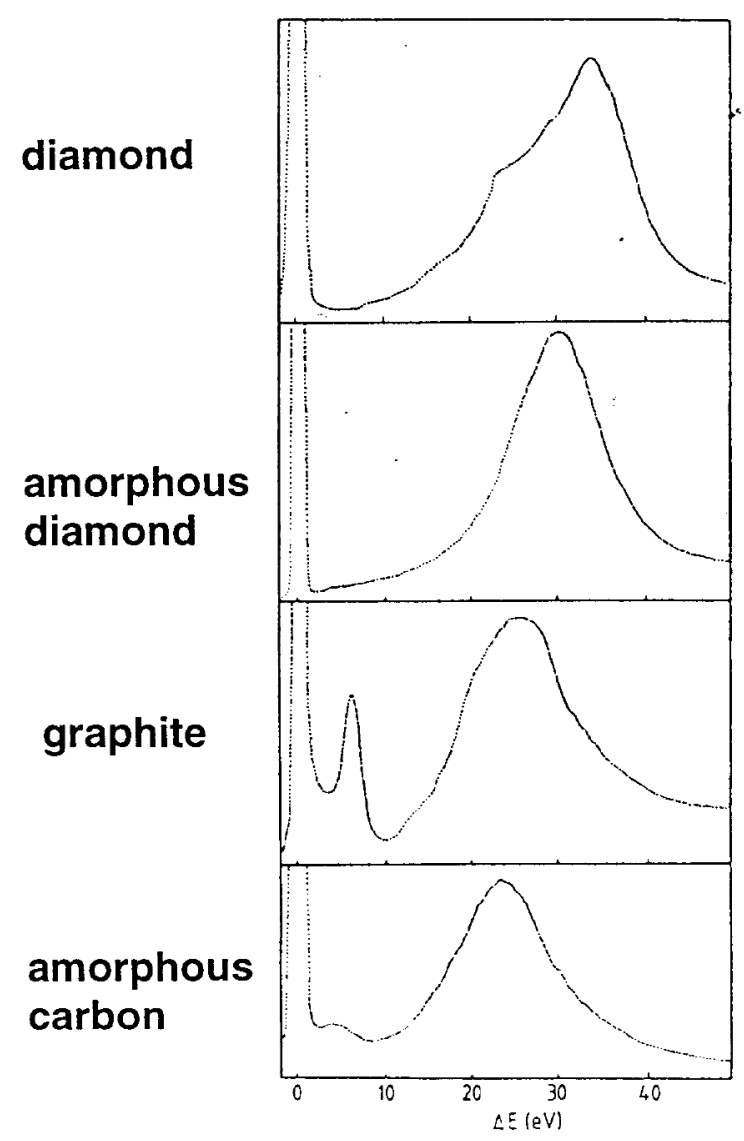

Fig. 13. EELS signatures for various phases of carbon films. ${ }^{9}$ 
shown in Fig. 15(b), a very broad peak centered near $1500 \mathrm{~cm}^{-1}$. This latter form is what we observed in all films tested with no significant variation in the Raman signal from film to film. Each response was a broad peak (approximately $300 \mathrm{~nm}$ FWHM) centered at $1520 \mathrm{~cm}^{-1}$ with one such spectrum shown in Fig. 16.

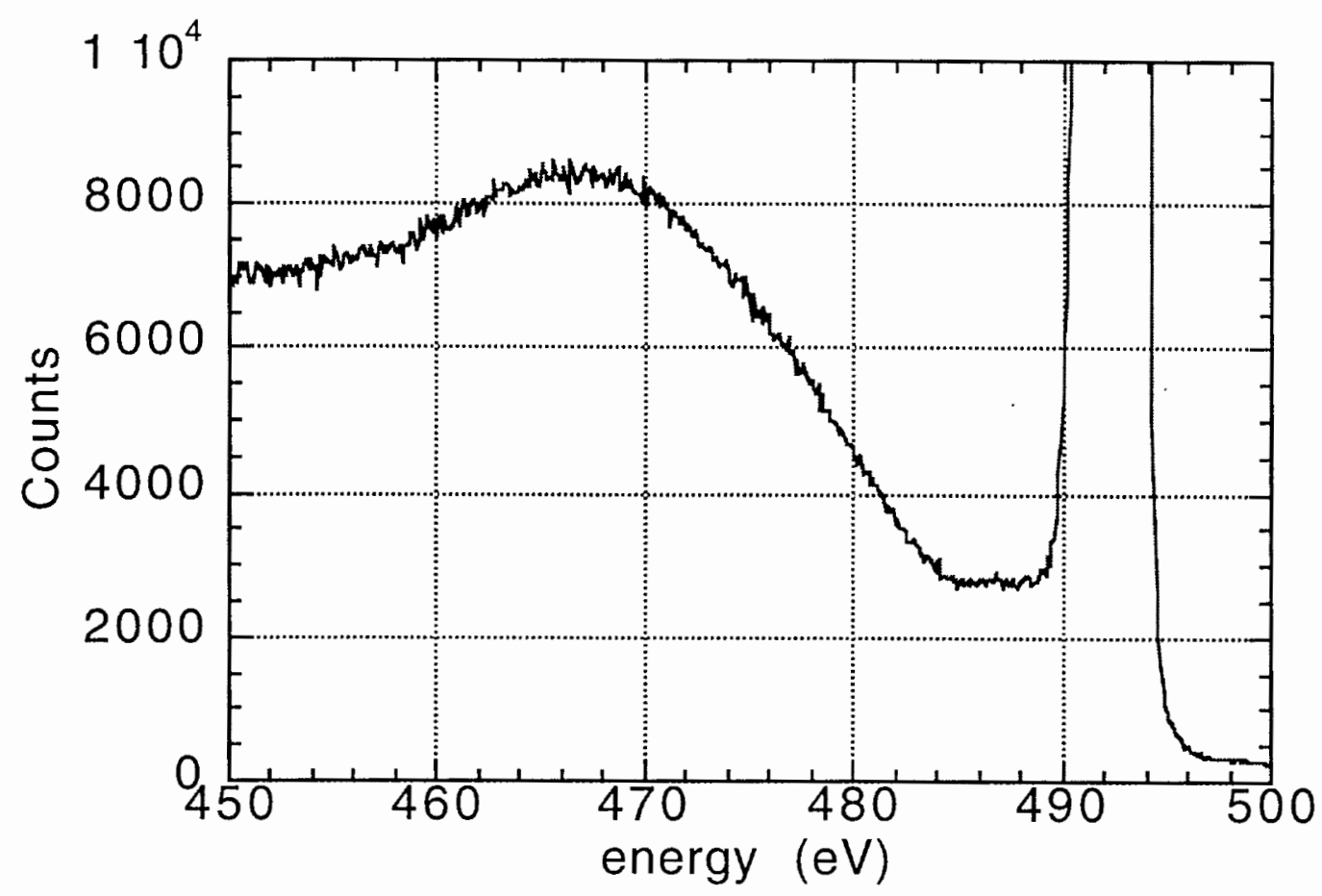

Fig. 14. EELS spectrum of DLC film. There is no peak near $5 \mathrm{eV}$ of the elasticly scattered peak at $493 \mathrm{eV}$, and the main peak is centered near $467 \mathrm{eV}$ (a shift of $26 \mathrm{eV}$ ).

Optical transmission measurements were also made using a spectrophotometer on samples grown on fused quartz disks $1 \mathrm{~mm}$ in thickness. The films are quite opaque, particularly in the visible, although this is not uncommon for DLC films. They are appreciably more transparent above $2-2.5 \mu \mathrm{m}$. It was not possible to investigate transmission further into the infrared due to absorption features in the substrate around $3 \mu \mathrm{m}$. Fig. 17 shows the transmission spectra for four different films grown under the same conditions $\left(1.4 \mathrm{~J} / \mathrm{cm}^{2}\right)$ with film thicknesses of $45 \mathrm{~nm}, 85$ $\mathrm{nm}, 160 \mathrm{~nm}$, and $610 \mathrm{~nm}$. The modulation for thicker films is due to thin film interference effects, 
and the bump at $850 \mathrm{~nm}$ is an artifact of changing detectors at this point. These modulations can be very large because of the relatively high index of refraction for diamond and other forms of carbon. In fact, for the thinner films, the loss above 1.5 $\mu \mathrm{m}$ is due almost entirely to the film acting as a reflective coating. Even so, the loss coefficients are several thousand inverse centimeters, typical of PLD films.

As was mentioned previously, although EELS would indicate that fluences larger than 1.4 $\mathrm{J} / \mathrm{cm}^{2}$ result in films less diamond-like in

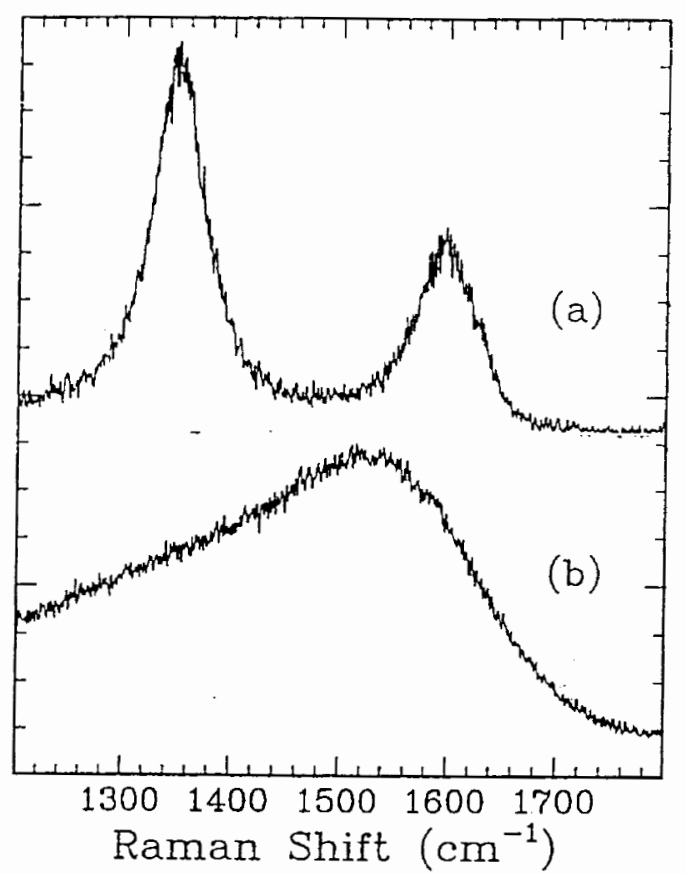

Fig. 15. Raman spectra for graphite (a) and amorphous "diamond-like" carbon(b). ${ }^{10}$

character, Fig. 18 shows that higher fluences

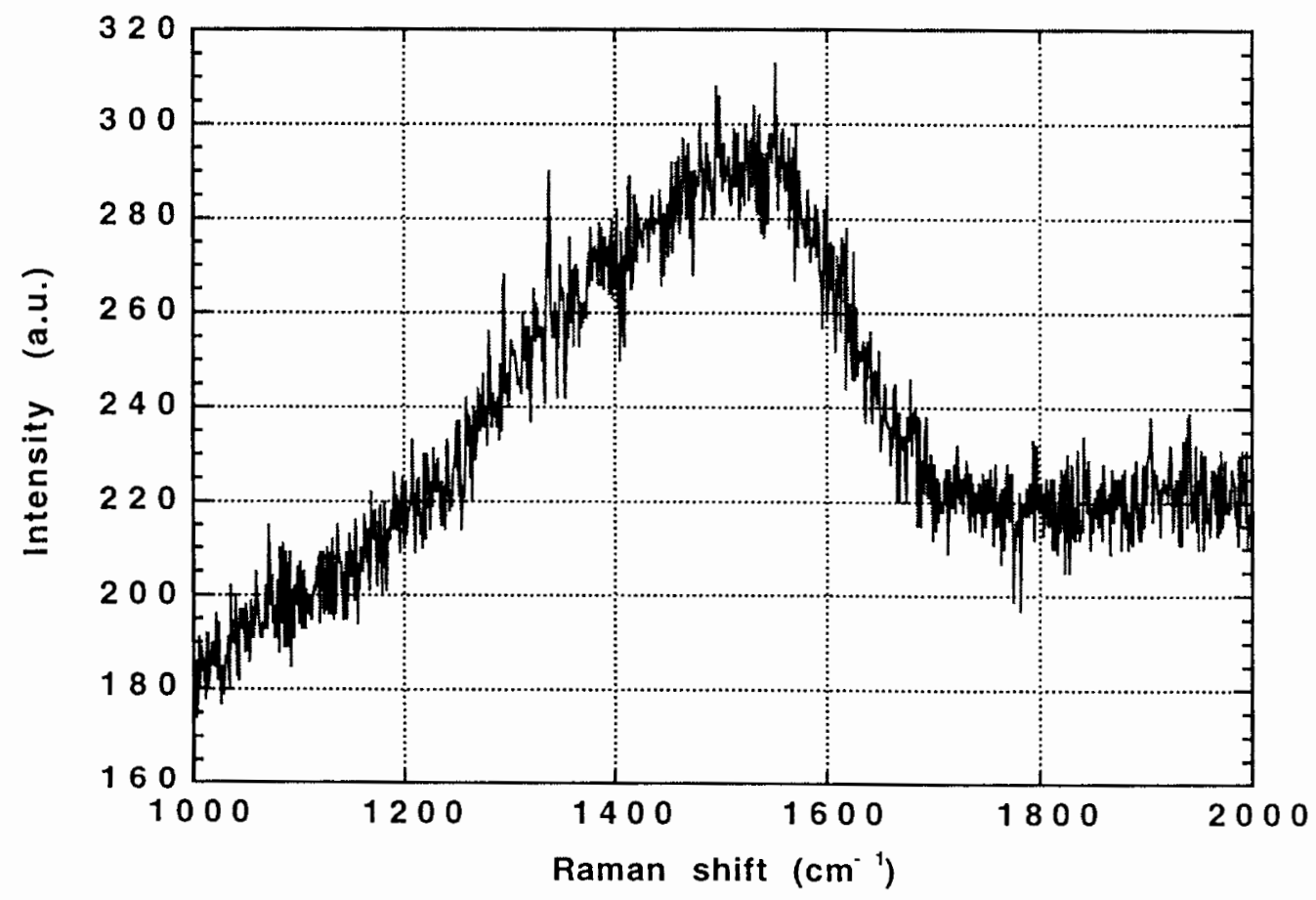

Fig. 16. Raman spectrum of DLC film. Peak centered at $1525 \mathrm{~cm}^{-1}$. 
result in films which are substantially more transparent. Fig. 18(a) shows two $45 \mathrm{~nm}$ thick films grown at $1.4 \mathrm{~J} / \mathrm{cm}^{2}$ and $25 \mathrm{~J} / \mathrm{cm}^{2}$ with the latter being the upper curve. In Fig. 18(b), the two films are $85 \mathrm{~nm}$ thick with the upper curve being grown at $14 \mathrm{~J} / \mathrm{cm}^{2}$.

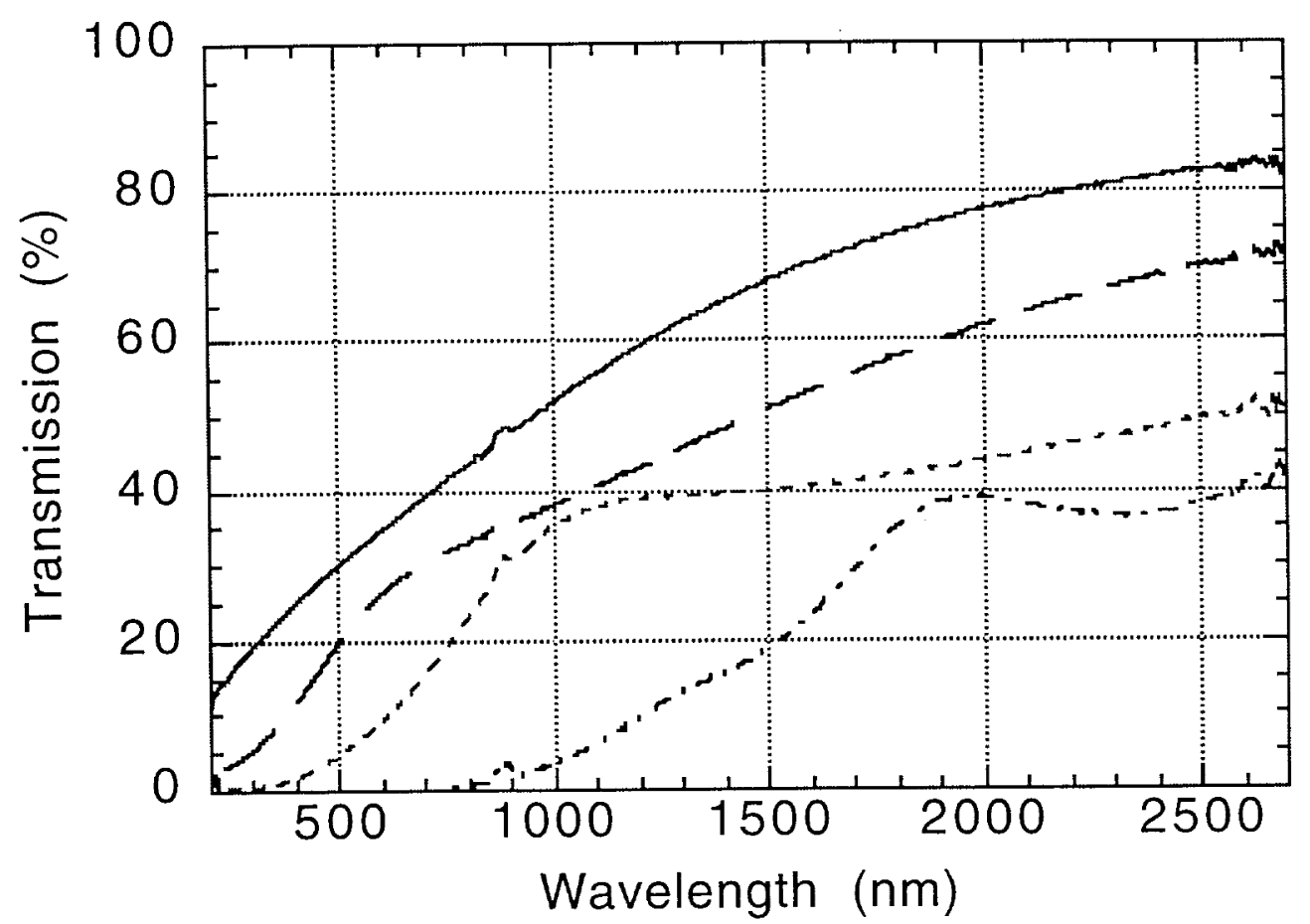

Fig. 17. Transmission spectra of DLC films of four thicknesses: $45 \mathrm{~nm}$ (solid), $85 \mathrm{~nm}$ (dashed), $160 \mathrm{~nm}$ (dotted), and $600 \mathrm{~nm}$ (dash-dotted). All films were grown at 1.4 $\mathrm{J} / \mathrm{cm}^{2}$ with $250 \mu \mathrm{m}$ spot and $75 \mathrm{~mm}$ target/substrate separation.

In an effort to determine the band gap of these films, spectral ellipsometry was used to fit the values of the real and imaginary part of the refractive index ( $n$ and $k$, respectively) as a function of wavelength. Using the values of $k$ obtained, we plotted $(\alpha \mathrm{E})^{1 / 2}$ as a function of photon energy (E) which is known as a Tauc plot. The $\mathrm{x}$-intercept of this curve should provide an estimate of the band gap of the material. The valued obtained is $.8 \mathrm{eV}$ which was insensitive to the model assumed in fitting $n$ and $k$. This is also in the typical range for DLC films, $.5-2 \mathrm{eV},{ }^{11}$ with about $1 \mathrm{eV}$ being most common. 

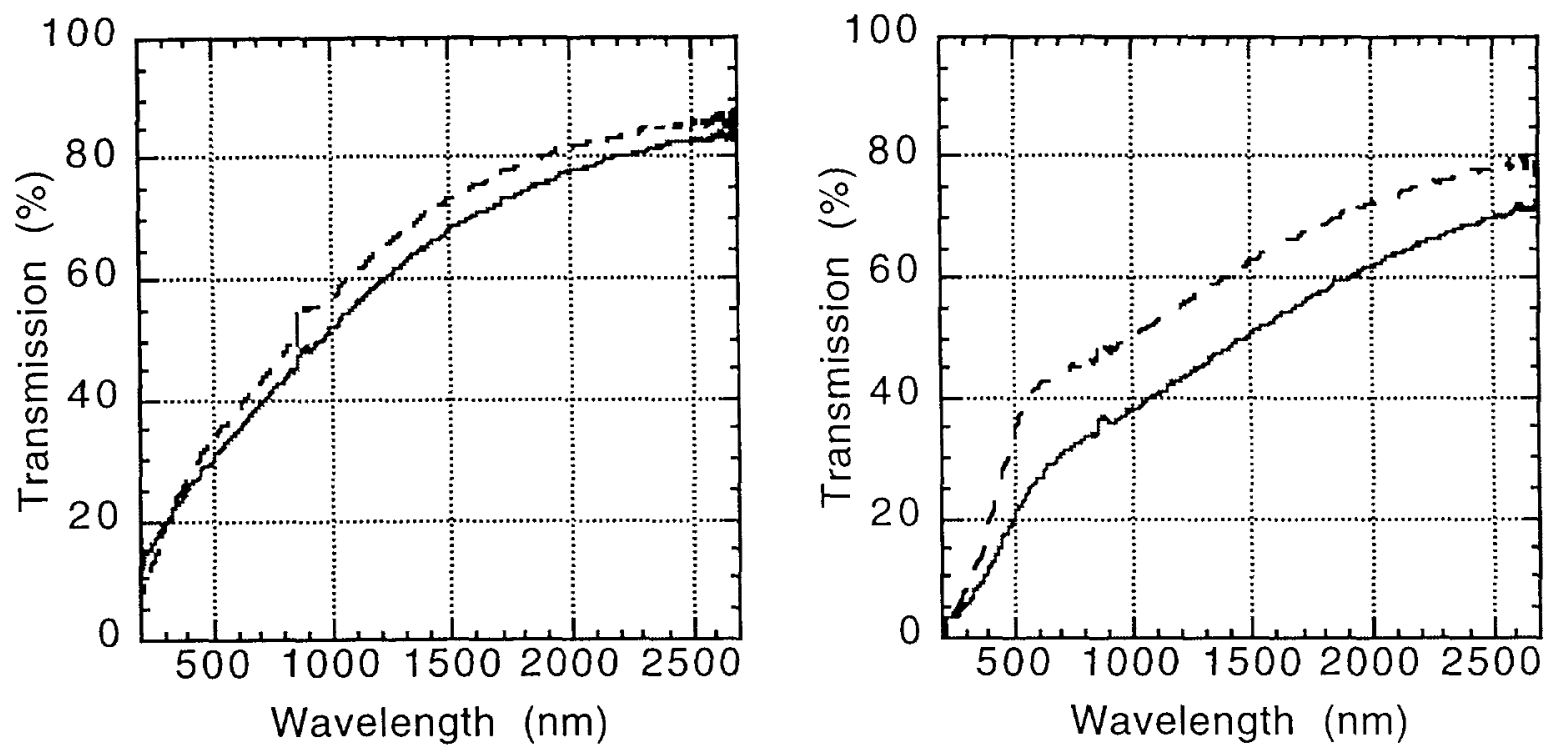

(a)

Fig. 18. Transmission spectra of DLC films. (a) $45 \mathrm{~nm}$ thick films grown at $1.4 \mathrm{~J} / \mathrm{cm}^{2}$ (solid) and $25 \mathrm{~J} / \mathrm{cm}^{2}$ (dashed). (b) ) $85 \mathrm{~nm}$ thick films grown at $1.4 \mathrm{~J} / \mathrm{cm}^{2}$ (solid) and $14 \mathrm{~J} / \mathrm{cm}^{2}$ (dashed).

Finally, Auger spectroscopy was performed on several of the films with only carbon and a small amount of oxygen being detected. The fine structure of the carbon signal had features which are typical again of amorphous DLC, and the oxygen signal was small and is likely due to subsequent surface contamination when the film is exposed to air. UV photoelectron spectroscopy was used to look at the band structure of the material, and a work function of $4.5 \mathrm{eV}$ was measured.

Processing of energetic materials. We also demonstrated the subpicosecond laser ablation process for laser machining (cutting and drilling) of high explosives, including pentaerythritol (PETN), trinitrotoluene (TNT), LX-14, PBX-9407, HNS, and TATB. Fourier transform infrared spectroscopy revealed no reaction products on the explosive surfaces after the cut. Line cuts 10 to $25 \mu \mathrm{m}$ wide were achieved through 2-mm-thick samples of explosive at rates exceeding $10 \mu \mathrm{m}$ of material removed per pulse (Fig. 19(a)). This is an order of magnitude higher than rates typically observed for metals and dielectrics. By comparison, the same laser configured by bypassing the pulse compressor for $0.5 \mathrm{~ns}$ pulses initiated deflagration before we could reach 


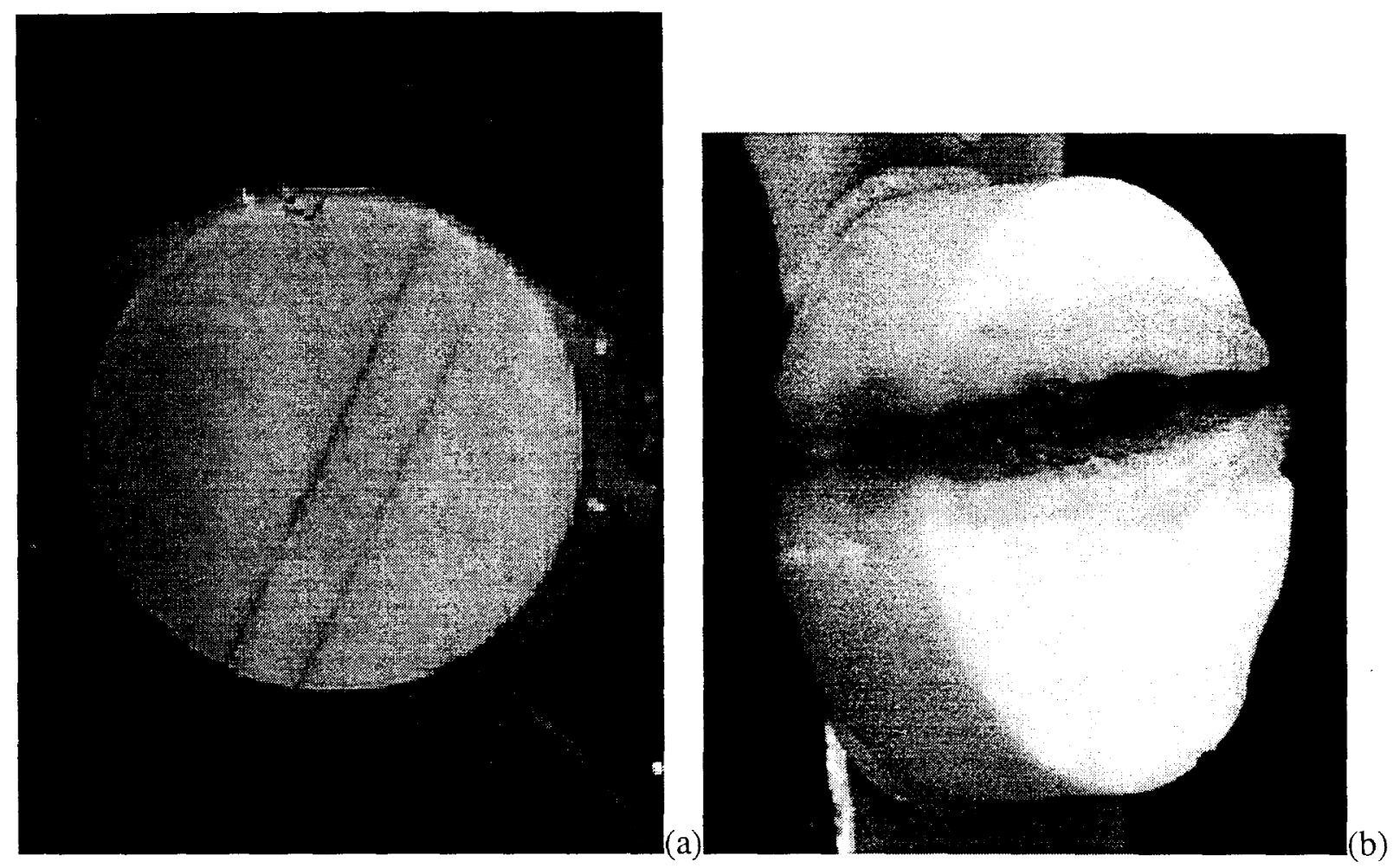

Fig. 19. Laser cutting of the high explosive pentaerythritol (PETN): (a) using subpicosecond pulses produced clean, narrow cuts, and (b) using nanosecond pulses initiated deflagration .

power densities needed for efficiently removing the material (Fig. 19(b)). Using subpicosecondclass lasers to precision machine high explosives promises to be a revolutionary technique with many possible applications.

\section{Conclusion}

Although it had been hoped to produce crystalline forms of diamond using femtosecond PLD, we were able to produce amorphous films of diamond-like carbon with properties typical of PLDproduced DLC. However, deposition rates up to $26 \mu \mathrm{m} / \mathrm{hr}$ were achieved which are much higher than even many CVD methods. CPA femtosecond laser systems running at $10 \mathrm{kHz}$ with average powers of $10-15 \mathrm{~W}$ are under development which would give deposition rates over $100 \mu \mathrm{m} / \mathrm{hr}$. We were able to easily produce films which were free of the macroscopic particulates which are typical of PLD-produced films whose surface roughness, for films thinner than $300-500 \mathrm{~nm}$, was primarily determined by that of the substrate. Finally, we demonstrated that the unique features 
characteristic of femtosecond laser ablation is ideal for the precision machining of energetic materials.

\section{References}

${ }^{1}$ W. McLean, B. E. Warner, M. A. Havstad, and M. Balooch, "Rapid growth of diamond-like carbon films by copper vapor laser ablation", Mat. Res. Soc. Symp. Proc. 388, 121-125 (1995).

${ }^{2}$ J. J. Cuomo, D. L. Pappas, J. Bruley, J. P. Doyle, and K. L. Sanger, "Vapor deposition processes for amorphous carbon films with $\mathrm{sp}^{3}$ fractions approaching diamond", J. Appl. Phys. 70, 1706-1711 (1991).

${ }^{3}$ P. T. Murrary and D. T. Peeler, "Dynamics of graphite photoablation: kinetic energy of the precursors to diamond-like carbon”, Appl. Surf. Sci. 69, 225-230 (1993).

${ }^{4}$ B. C. Stuart, M. D. Feit, S. Herman, A. M. Rubenchik, B. W. Shore, and M. D. Perry, "Nanosecond to femtosecond laser-induced breakdown in dielectrics", Phys. Rev. B 53, 17491761 (1996); B. C. Stuart, M. D. Feit, S. Herman, A. M. Rubenchik, B. W. Shore, and M. D. Perry, "Optical ablation by high-power short-pulse lasers", J. Opt. Soc. Am. B 13, 459-468 (1996).

${ }^{5}$ F. Müller, K. Mann, P. Simon, J. S. Bernstein, and G. J. Zaal, “A comparative study of deposition of thin films by laser induced PVD with femtosecond and nanosecond laser pulses", Proc. SPIE 1858, 464-475 (1993).

${ }^{6}$ F. Qian, R. K. Singh, S. K. Dutta, and P. P. Pronko, "Laser deposition of diamondlike carbon films at high intensities", Appl. Phys. Lett. 67, 3120-3122 (1995).

${ }^{7}$ A. Borghesi and G. Guizzetti in Handbook of Optical Constants of Solids II, ed. E. D. Palik, Academic Press, New York, 1991.

${ }^{8}$ P. J. Fallon and L. M. Brown, "Analysis of chemical-vapour-deposited diamond grain boundaries using transmission electron microscopy and parallel electron energy loss spectroscopy in a scanning transmission electron microscope", Diamond Rel. Mat. 2, 1004-1011 (1993).

${ }^{9}$ S. D. Berger, D. R. McKenzie, and P. J. Martin, "EELS analysis of vacuum arc-deposited diamond-like films", Phil. Mag. Lett. 57, 285-290 (1988).

${ }^{10}$ P. T. Murray and D. T. Peeler, "Pulsed laser deposition of carbon films: dependence of film properties on laser wavelength", J. Elect. Mat. 23, 855-859 (1994).

${ }^{11}$ D. L. Pappas, K. L. Saenger, J. Bruley, W. Krakow, and J. J. Cuomo, "Pulsed laser deposition of diamond-like carbon", J. Appl. Phys. 71, 5675-5684 (1992). 